\title{
FORMAÇÃO PROFISSIONAL EM REDE: MOOC DE REDAÇÃO OFICIAL EM LIBREOFFICE WRITER
}

\author{
RED DE FORMACIÓN PROFESIONAL: MOOC DE REDACCIÓN DE \\ DOCUMENTOS OFICIALES EN LIBREOFFICE WRITER
}

\section{PROFESSIONAL QUALIFICATION NETWORKING: MOOC OF OFFICIAL WRITING IN LIBREOFFICE WRITER}

\author{
Liliane Silveira BONORINO ${ }^{1}$ \\ Ilse $\mathrm{ABEGG}^{2}$
}

RESUMO: Este estudo objetiva inovar na oferta de formação mediada pelas Tecnologias Educacionais em Rede (TER) através de um MOOC (Massive Open Online Courses - Cursos On-line Abertos e Massivos), pela plataforma Moodle (Modular Object Oriented Dynamic Learning Enviroment). Esta pesquisa foi implementada em duas fases: 1) módulo-piloto, a fim de verificar se a organização didático-metodológica estava bem encaminhada; e 2) $M O O C$, para promover a formação profissional e o aprimoramento de conhecimentos acerca da redação oficial em LibreOfffice Writer. Após a análise dos dados coletados no $M O O C$, constatou-se que houve processo de ensino-aprendizagem mediado pelas Tecnologias Educacionais em Rede (TER), dado que promoveu a formação profissional dos envolvidos.

PALAVRAS-CHAVE: Formação profissional em rede. MOOC. Redação de documentos oficiais. LibreOffice Writer.

RESUMEN: Este estudio tiene como objetivo innovar en la oferta de formación mediada por la tecnología de red para la Educación (TER) a través de un MOOC (Massive Open Online Courses - Cursos en línea abiertos y masivos), disponible en Moodle (Modular Object Oriented Dynamic Learning Enviroment). Esta investigación se realizo en dos fases: 1) Primera fase, denominada "módulo-piloto", con el fin de comprobar si el material del curso tenía una buena organización didáctica y metodológica., 2) MOOC para desarrollar la formación profesional y la mejora del conocimiento sobre La Redacción de documentos oficiales en LibreOffice Writer. Después de analizar los datos recogidos en el MOOC, el desarrollo del proceso de enseñanza-aprendizaje mediado por la red de tecnología de la educación se verificó, tal como lo promueve la formación de los implicados.

\footnotetext{
${ }^{1}$ Doutoranda do Programa de Pós--Graduação em Educação da Universidade Federal de Santa Maria (UFSM), Mestre em Tecnologias Educacionais em Rede (UFSM). Email: lilibonorino@gmail.com

2 Professora Adjunta do Departamento de Metodologia do Ensino da Universidade Federal de Santa Maria, atuando nos Programas de Pós-Graduação em Educação e Tecnologias Educacionais em Rede. Pesquisadora FAPERGS e Universidade Aberta do Brasil (UAB/UFSM). Possui doutorado em Informática na Educação pela UFRGS e Mestrado em Educação Científica e Tecnológica pela UFSM. Graduada em Pedagogia pela UFSM. E--mail: ilse.abegg@ufsm.br
} 
PALAVRAS CLAVE: Red de formación profesional. MOOC. Redacción de documentos oficiales. LibreOffice Writer.

ABSTRACT: This study aims to innovate in the training provision mediated by Educational Technology Network (ETN) through a MOOC (Massive Open Online Courses - Online Courses Open and Massive) for Moodle (Modular Object Oriented Dynamic Learning Enviroment). This research is based on considerations of Freire (1967), which, through dialogue, problem-solving, it is possible to the subject reflect on their professional practice in order to realize its potential to transform them. In this context, this research was implemented in two phases: 1) pilot module, in order to verify that the didactic-methodological organization was well underway and, 2) MOOC to promote professional training and improvement of knowledge about the official writing in LibreOfffice Writer. After analyzing the data collected in the MOOC, it was found that there were teaching-learning process mediated by educational technology network, as promoted the training of those involved.

KEYWORDS: Professional qualification networking. MOOC. Official document writing. LibreOffice Writer.

\section{Introdução}

$\mathrm{Na}$ atualidade, têm-se diversas pesquisas sobre a integração das Tecnologias Educacionais em Rede (TER) nas práticas dos profissionais, no entanto, falta um devido suporte a estes para, em alguns casos, implementá-las em contextos existenciais de trabalho. Então, como exigir que os diversos profissionais integrem no seu contexto de trabalho a tecnologia se a desconhecem e não tiveram uma devida formação para implementá-la em sua prática? Dessa forma, vê-se a necessidade não só da oferta de um material didático para suprir essa demanda, como também se percebe a importância de disponibilizar uma formação em rede. Então, por que não viabilizar formação profissional em rede via $M O O C$ ?

Ao fazer essas reflexões acerca da situação de diversos profissionais, como os Técnicos-Administrativos em Educação (TAE), verificou-se a necessidade de promover pela plataforma Moodle (Modular Object Oriented Dynamic Learning Enviroment) um MOOC (Massive Open Online Courses - Cursos On-line Abertos e Massivos) de redação oficial em LibreOffice Writer, ou seja, dando-se o enfoque a essa ferramenta computacional aberta e livre para a produção de textos oficiais. Isso porque se percebeu a necessidade não só da oferta de um material didático para suprir essa demanda, como também se vê a importância de disponibilizar uma formação deste cunho. 
Acredita-se que a oferta de cursos de formação na modalidade de Educação a Distância (EAD), sob a perspectiva de $M O O C$, ou seja, de livre acesso na Internet, seja uma alternativa viável para capacitar os diversos profissionais. Tal afirmação deve-se ao fato de que hoje as novas demandas em todos os contextos profissionais requerem um profissional atualizado, preocupado com o seu aprimoramento e que esteja disposto a se aperfeiçoar, a engajar-se na sua qualificação profissional, sendo a modalidade EAD um veículo que proporciona a construção de uma rede.

Por fim, esta pesquisa faz parte da dissertação intitulada " $M O O C$ de redação oficial em LibreOffice Writer", apresentada ao Programa de Pós-Graduação em Tecnologias Educacionais em Rede (PPGTER), da Universidade Federal de Santa Maria (UFSM), e justificou-se pela sua relevância em valorizar a formação profissional em rede, a qual pode ser promovida pela EAD, flexibilizando o seu acesso no tempo e no espaço. Assim, esta oferta permite o estabelecimento de uma rede virtual de formação, a qual "constitui-se em um 'espaço propício ao desenvolvimento profissional" (BECKER, 2013, p. 4). E é este espaço de desenvolvimento profissional, no que diz respeito à redação de documentos em LibreOffice Writer, que o MOOC visou estabelecer em sua rede de aprendizagem.

\section{Uma proposta de inserção do LibreOffice Writer como ferramenta digital livre no contexto profissional}

Em face das grandes transformações ocasionadas pela revolução digital, faz-se necessário pensar em formas de acompanhar os avanços tecnológicos em todos os âmbitos, inclusive no educacional. Nesse sentido, buscam-se maneiras de inserir as TER no dia a dia dos profissionais que trabalham nos mais diversos setores.

No que concerne ao mundo do trabalho nesta era digital, os profissionais de todas as esferas, inclusive da educacional, têm procurado cursos que visam suas atualizações. Gabriel (2013) considera que, atualmente, a necessidade de atualização constante requer que se estude o tempo todo, e a educação passou a ser uma vertente importante na denominada "Era Digital”. E é assim que os diversos profissionais têm procurado se manter: atualizados diante das demandas sociais.

Conforme Gabriel (2013), as Tecnologias de Informação e Comunicação (TIC) trouxeram mudanças nos paradigmas educacionais, visto que estas antes eram focadas no professor e agora passam a ser distribuídas, ocasionando uma transformação que 
alavanca a colaboração, oportuniza o desenvolvimento da criatividade, da inovação e do pensamento direcionado para a solução de problemas. Nesse sentido, tem-se uma educação voltada para a formação de profissionais abertos à criatividade, à colaboração, à reflexão, e, principalmente, dispostos a resolver os problemas de situações existenciais.

Vive-se em um mundo no qual as pessoas estão conectadas o tempo inteiro e esta situação se reflete também no mundo do trabalho contemporâneo. De acordo com Pochmann (2012, p. 492),

[...] nota-se a extensão do trabalho para além do exclusivo local de sua realização. Isto é, a possibilidade do exercício crescente do trabalho imaterial em qualquer local, sobretudo com o uso de novas tecnologias de comunicação e informação que tornam o ser humano quase que plugado 24 horas por dia no trabalho heterônomo.

Seguindo essa perspectiva, por que não ofertar aos diversos profissionais uma formação através das redes digitais? Aproveita-se o momento e o ensejo para, através de $M O O C$, oportunizar um espaço de formação profissional.

Segundo Gabriel (2013), as organizações que se adaptam às mudanças provocadas pela revolução digital são as que evoluem e têm sucesso. A autora afirma ainda que a adaptabilidade digital permite que os indivíduos alcancem o sucesso na era digital. Refletindo nesse viés, por que não oportunizar uma formação em rede através de cursos EAD voltados para a integração das TIC no seu contexto profissional?

Nesse viés, para Veloso (2011), as TIC são pensadas como instrumentos de mediação, que podem ser usadas para otimizar os processos de trabalho e potencializar o exercício profissional. Assim, a mediação das TIC no contexto profissional,

[...] trata-se de um recurso que possui potencial estratégico para o trabalho. Sua importância reside na possibilidade de potencializar, de imprimir uma mudança qualitativa ao trabalho profissional, a partir de seu uso como recurso capaz de propiciar a ampliação das capacidades e habilidades profissionais (VELOSO, 2011, p. 32).

Desse modo, Veloso (2011) sustenta a relevância das TIC para o exercício profissional, alegando que, ao promover sua integração, podem-se criar condições para a melhoria do exercício profissional, sendo, por isso, consideradas fatores potencializadores do trabalho. 
Nessa perspectiva, espera-se que, oportunizar uma formação em rede através de um "MOOC de redação oficial em LibreOffice Writer", seja uma estratégia não só de disseminar a possibilidade da implementação de um Software Livre (SL), mas também de integração de uma TIC em seu contexto profissional e/ou pessoal.

E, por falar na integração das TIC no âmbito profissional, no que diz respeito às tecnologias e às revoluções causadas por elas nos mais diversos lugares, de acordo com Gabriel (2013), o importante em uma revolução tecnológica não é a tecnologia em si, mas sim o que se faz com ela para melhorar a vida, ou seja, os benefícios trazidos por ela. Então, pode-se procurar não só entender, como também implementar as possibilidades de integração do aparato digital que possam auxiliar os diversos profissionais na melhoria da produção do trabalho. Isto ocorre devido ao fato de que as demandas dos tempos atuais do contexto profissional exigem uma constante atualização e uma capacitação para a integração das mídias digitais.

Um dos grandes problemas atuais do mercado e instituições é a falta de educação digital e de pensamento estratégico em relação às mídias digitais. [...] Depois da capacitação, o passo natural é o investimento em automatização e ferramentas que possibilitem o aumento da produtividade (GABRIEL, 2013, p. 7).

Do exposto, reflete-se na possibilidade de ofertar, por meio de $M O O C$, uma capacitação voltada para a integração de uma ferramenta livre, o LibreOffice Writer, para a produção de documentos oficiais. Tal MOOC assinala uma iniciativa de ofertar uma formação em rede, a fim de não só qualificar os cursistas, como também de incentivá-los a integrar uma TIC livre à sua prática de edição de documentos. Consequentemente, espera-se que esses reconheçam a importância da integração das TIC no âmbito profissional, uma vez que estas auxiliam na produtividade de alguns serviços administrativos com os quais se utilizam o computador, dando um devido suporte técnico e operacional.

Dessa forma, ao disponibilizar um MOOC que tem como proposta uma formação em rede destinada à capacitação de seus cursistas no que se refere à produção de documentos em LibreOffice Writer, vê-se a possibilidade da inserção da tecnologia no contexto profissional. Isso pode resultar em melhorias nas atividades-fim dos setores, na qual, juntos e engajados, possam estabelecer uma rede de compartilhamento de saberes acerca da produção de documentos oficiais em LibreOffice Writer. Tal produção, 
por sua vez, sendo aperfeiçoada e embasada em uma ferramenta livre, tem potencialidade para gerar inovação no seu ambiente de trabalho.

Seguindo o viés da colaboração e do compartilhamento de saberes, para consolidá-los, adota-se o Moodle como plataforma educacional livre e aberta para oferta do MOOC. Uma versão desse Ambiente Virtual de Ensino-Aprendizagem (AVEA) está instalada para a realização das atividades do grupo de pesquisa "Investigação-Ação e Educação Dialógico-Problematizadora Mediada por Tecnologias Livres" e faz parte do Laboratório de Ambiente Virtual de Ensino-Aprendizagem Livre e Aberto (Laveala) da Universidade Federal de Santa Maria (UFSM), o qual pode ser acessado no seguinte endereço eletrônico: http://laveala.proj.ufsm.br/.

O Moodle é uma plataforma educacional, que se configura colaborativo, uma vez que, baseado em computador, "auxilia grupos de pessoas envolvidas em tarefas comuns (ou objetivos)". (ABEGG; BASTOS; MÜLLER, 2009, p. 64). Portanto, é uma plataforma utilizada para apoio ao ensino-aprendizagem virtual, que permite o compartilhamento de materiais didáticos e possibilita a realização de um trabalho colaborativo em rede.

\section{Formação profissional: um modo de produção em rede na perspectiva de educação para a liberdade}

Um $M O O C$ de formação profissional voltado para um modo de produção na perspectiva de educação para liberdade consiste em oportunizar " [...] aos envolvidos a 'liberdade de produção' e, consequentemente, de desenvolvimento da autonomia, ou seja, da tomada de decisão" (ABEGG; BASTOS; MÜLLER, 2009, p. 71). E é nesse sentido que o MOOC foi ofertado, a fim de permitir que os cursistas tenham a liberdade para produzir documentos oficiais, mediados pelo LibreOficce Writer, além de poderem baixar o material didático, editá-lo e compartilhá-lo, livremente.

No que diz respeito à Educação como Prática da Liberdade (EPL), com base nas considerações de Freire (1967), depreende-se que, através do diálogo-problematizador, possibilita-se ao sujeito refletir sobre si mesmo no mundo e com o mundo, a fim de que perceba seu potencial para transformá-lo, e torná-lo melhor. Ou seja, o sujeito torna-se ativo não só no processo de ensino-aprendizagem, como também no processo de transformação de sua realidade. É isto que o presente $M O O C$ ofereceu aos envolvidos 
nesse processo: um espaço em rede capaz de proporcionar mudanças significativas em suas condutas profissionais no que concerne à integração das TER livres e produção de documentos oficiais, ou seja, os cursistas foram capacitados para transformar os seus contextos profissionais através da adoção da ferramenta LibreOffice Writer.

Na EPL, tem-se um movimento educacional que está embasado na "Liberdade cultural, condição necessária para a colaboração e o desenvolvimento da autonomia. Somente na sociedade é que somos livres, pois é na interação com o outro que construímos a liberdade [...]" (ABEGG; BASTOS; MÜLLER, 2009, p. 71). Portanto, a EPL possibilita que o sujeito se torne uma pessoa mais ativa e crítica para refletir, pensar e agir.

Nessa perspectiva, julga-se que um $M O O C$, voltado para a prática da liberdade, possa despertar o engajamento dos participantes envolvidos para que estes sejam sujeitos ativos e colaborativos do processo ensino-aprendizagem.

Para tanto, esta formação profissional foi oportunizada pela EAD, que, segundo Becker (2013), permite que sejam estabelecidas relações favoráveis ao desenvolvimento de redes de formação e ao aperfeiçoamento profissional. Por isso, justifica-se a escolha pela plataforma Moodle para ofertar o curso nessa modalidade de ensino-aprendizagem.

Ao disponibilizar um $M O O C$, oportunizou-se um espaço de formação profissional mediado pelas redes. E, para melhor compreender o que significa redes, a seguir tem-se a conceituação de Kenski (2012, p. 34):

\footnotetext{
As redes, mais do que uma interligação de computadores, são articulações gigantescas entre pessoas conectadas com os mais diferenciados objetivos. A internet é o ponto de encontro e dispersão de tudo isso. Chamada de rede das redes, a internet é o espaço possível de integração e articulação de todas as pessoas conectadas com tudo o que existe no espaço digital, o ciberespaço.
}

Do exposto, acredita-se que um curso em rede pode proporcionar um processo de desenvolvimento profissional, uma vez que se constitui em um espaço de integração e articulação entre as pessoas conectadas, gerando participação e colaboração em seus quefazeres.

Abegg, Bastos e Müller (2009) consideram a participação na produção à distância mediada pelas TER livres como um processo de produção do conhecimento que potencializa a comunicação e a colaboração, visto que a Internet é um espaço essencialmente colaborativo. 
Sendo assim, na oferta de formação profissional na perspectiva de educação para a liberdade, tem-se um movimento de libertação do software proprietário, uma vez que é dada a opção aos participantes do curso de redação oficial, através dessa ferramenta livre, de emancipar-se, assinalando, assim, sua autonomia tecnológica.

E é assim que MOOCs poderiam ser ofertados, numa perspectiva de educação para a liberdade, ampliando e potencializando o desenvolvimento profissional em rede dos diversos profissionais.

\section{MOOC: conceituação e sua representação na educação}

Massive Open Online Courses (MOOCs) são cursos abertos e livres, sendo ofertados em rede a um número massivo de participantes. Cabe observar que nem todos os MOOCs têm acesso livre, pois precisam de cadastro. No caso da presente pesquisa, para fins de coleta e análise dos dados, também foram cursistas cadastrados que tiveram acesso ao "MOOC de redação oficial em LibreOffice Writer". Porém, cabe destacar que o mesmo será disponibilizado de forma libre e aberta, sem restrição de acesso no endereço citado anteriormente.

Cabe observar que o referido MOOC está estruturado contemplando a perspectiva da prática dialógico-problematizadora, ou seja, contém situações existenciais que problematizam o cotidiano da produção dos documentos oficiais. Sendo assim, em vista do seu potencial de oferta, escolheu-se essa modalidade de ensino para disponibilizar o presente curso, uma vez que vê-se nela a possibilidade de disponibilizar uma educação aberta, promovendo uma formação livre e em rede a um número massivo de interessados a fazê-lo, a reaproveitá-lo ou a reutilizá-lo em seus contextos profissionais e/ou pessoais.

Conforme Mallmann et al. (2013, p. 3), os MOOCs representam inovação na educação, uma vez que “[...] são cursos abertos mediados por ferramentas da web 2.0, como as plataformas de gerenciamento de conteúdos e aprendizagem”. Ainda, os autores destacam que este formato de educação on-line difere de outros cursos à distância devido aos seguintes aspectos: não exige pré-requisitos para participação; para acesso ao conteúdo, não apresenta ordenamento sequencial e linear; possibilita a participação de um número massivo de cursistas; possui recursos e atividades abertos e mediados por tecnologias em rede. Dessa forma, ofertou-se um MOOC diretivo, ou seja, que direciona para o aperfeiçoamento no que diz respeito à redação de documentos oficiais em LibreOffice Writer. 
Pode-se dizer que a educação promovida por $M O O C$, além de ser aberta, “[...] é um movimento de pessoas e instituições que promovem ações que têm como objetivo tornar a educação mais livre e acessível para todos" (INUZUKA e DUARTE, 2012, p. 194). Então, por que não aproveitar este tipo de ambiente educacional para promover uma formação em rede a um número maior de pessoas?

Os MOOCs são ofertados via web, por meio de AVEA ou de redes sociais, e oportunizam a um vasto público, através de um processo de coprodução, a possibilidade de ampliação de seus conhecimentos. Por isso, diferenciam-se das iniciativas tradicionais de ofertas EAD, como também por serem gratuitos (em sua maioria) e de curta duração (BARIN e BASTOS, 2013).

Deste modo, ao disponibilizar um curso de formação em rede através de $M O O C$, pretende-se gerar um espaço de coprodução de conhecimentos, de compartilhamento de experiências de aprendizagens, as quais podem ser reaproveitadas em outros contextos. Tal estratégia de ensino pode ser considerada inovadora, uma vez que pode ocasionar uma inovação, seja no contexto profissional e/ou pessoal. Assim, na educação através da modalidade $M O O C$, vê-se uma nova concepção de ensino mediada por TER.

Barin e Bastos (2013) afirmam que, além de atenderem as demandas da sociedade, os cursos abertos on-line representam tendência de inovação para o ensino, uma vez que podem ser realizadas com menos custo e maior flexibilidade. Então, visando atender às necessidades constantes nesta sociedade no que concerne à formação em rede, este curso foi realizado sem custo e com flexibilidade para seu acesso.

Enfim, este tipo de curso viabiliza a flexibilidade do ensino e assinala uma educação mediada por tecnologias em rede, promovendo, assim, o compartilhamento do conhecimento e o processo de ensino-aprendizagem em rede.

\section{Procedimentos metodológicos empregados no presente estudo}

Para o desenvolvimento deste trabalho, adotou-se a pesquisa-ação, que implicou na realização de um estudo acerca da formação em rede, proporcionada por um " $M O O C$ de redação oficial em LibreOffice Writer".

Segundo Carr e Kemmis (1986, p. 162), “[...] a pesquisa-ação consiste em uma forma de investigação autorreflexiva dos envolvidos, a fim de melhorar as suas situações, bem como as suas práticas". Nesse viés, ao investigar as potencialidades de 
um $M O O C$ voltado para o melhoramento da produção de documentos oficiais em LibreOffice Writer, os envolvidos nesse processo de formação profissional tiveram a oportunidade de autorrefletir acerca de sua formação anterior e pós-curso. Assim acredita-se que, esse processo de investigação autorreflexivo por meio desse $M O O C$, não só interferiu na prática atual realizada pelos cursistas, como também apresentou potencial para alterá-la e aprimorá-la, a partir da utilização do LibreOffice Writer, implementando a integração de uma ferramenta aberta e livre no processo de produção profissional.

O presente estudo foi dividido em dois momentos: no módulo-piloto do " $\mathrm{MOOC}$ de redação oficial em LibreOffice Writer", realizado em novembro de 2015; e, no MOOC, que foi implementado em junho de 2016. O módulo-piloto consistiu na ação inicial de fazer um levantamento estratégico para avaliar o material didático do $M O O C$. Nesse módulo-piloto, trabalhou-se com a diagramação de documentos oficiais através da ferramenta LibreOffice Writer, ou seja, de sua formatação. Já no MOOC de Redação Oficial em LibreOffice Writer, verificou-se se o curso e seu material didático contribuíram para a formação em rede dos envolvidos nesse processo de ensinoaprendizagem.

No módulo-piloto, a coleta de dados foi realizada a partir de dois instrumentos: - da atividade de estudo realizada e enviada pelos participantes pela plataforma Moodle, que foi desenvolvida com intuito de verificar se o conteúdo abordado no módulo-piloto foi apreendido pelos participantes;

- de um questionário on-line de avaliação do material didático do curso, a fim de fazer um levantamento estratégico para avaliar se o material didático e a estratégia adotada para abordar a redação oficial, a partir da ferramenta LibreOffice Writer, foram considerados claros e coerentes com as expectativas dos seus participantes, e se estes tiveram boa compreensão dos conteúdos.

Já para o MOOC, realizado em junho de 2016, a coleta de dados ocorreu pelos seguintes instrumentos:

- através de cinco atividades de estudo, sendo realizada uma em cada módulo;

- pelas interações dialógico-problematizadoras estabelecidas pelo espaço "Comentários ao envio", disponível em cada atividade de estudo proposta; e no espaço "Mensagens"; - de uma pesquisa on-line de avaliação do curso e do material didático. 


\section{Resultados}

Com a realização da primeira fase desta pesquisa, o módulo-piloto, após análise dos dados coletados, constatou-se que foi gerado o processo de ensino-aprendizagem como prática da Liberdade (Freire, 1967) e que a organização didático-metodológica do curso estava bem encaminhada para a realização do MOOC (fase posterior dessa pesquisa). Sendo assim, considera-se que os objetivos propostos para a sua implementação foram alcançados, uma vez que o material didático e a estratégia adotada para abordar a redação oficial em LibreOffice Writer foram compreendidos e estavam de acordo com as necessidades de formação dos envolvidos.

Quanto à avaliação do material didático, os três participantes do módulo-piloto atribuíram-lhe uma nota, conforme ilustrado na Figura 1:

Figura 1: Avaliação do material didático do curso

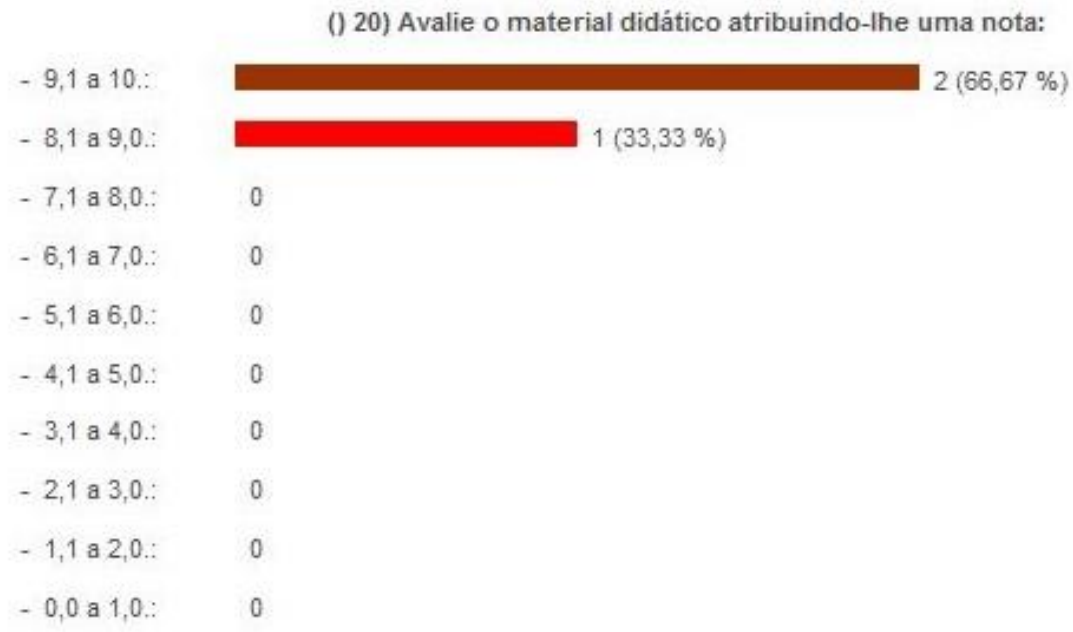

Fonte ${ }^{3}$

Das três repostas, obteve-se o seguinte: dois participantes atribuíram-lhe de 9,1 a 10,0; e um deles atribui-lhe de 8,1 a 9,0. Com base nesta avaliação, concluiu-se que o material didático foi considerado excelente.

Portanto, após a análise e descrição dos dados obtidos no questionário on-line, pode-se afirmar que, no geral, o material didático e a estratégia adotada para abordar a

3 Moodle Laveala, disponível no link:<http://laveala.proj.ufsm.br/mod/feedback/analysis.php? id=1731\&courseid\&do_show=analysis $>$. 
redação oficial em LibreOffice Writer foram bem-sucedidos e apresentaram potencial para gerar processo de ensino-aprendizagem em rede. Observa-se que alguns aspectos apontados pelos participantes serviram para replanejar não só o material didático, como também a próxima ação, que foi desenvolvida no segundo momento desta pesquisa.

No segundo momento da pesquisa, após a implementação do $M O O C$, os cursistas avaliaram-no, bem como o seu material didático.

Na Figura 2 tem-se o levantamento acerca da avaliação do curso.

Figura 2: Avaliação do $M O O C$

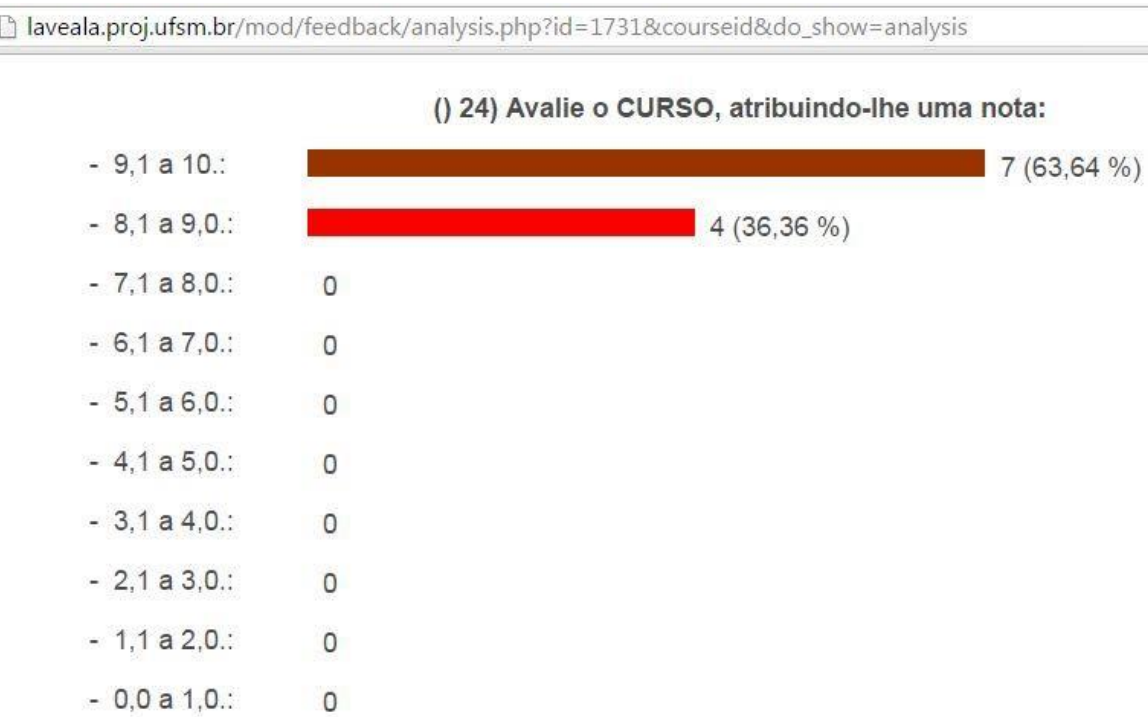

Fonte $^{4}$

Dessa análise, apurou-se o seguinte: 7 cursistas $(63,64 \%)$ atribuíram-lhe a nota de 9,1 a 10,0; e 4 cursistas $(34,36 \%)$, de 8,1 a 9,0. Dessa maneira, concluiu-se que o $M O O C$ foi considerado excelente.

E, na Figura 3, tem-se o levantamento acerca da avaliação do material didático do $M O O C$.

4 Moodle Laveala, disponível no link: <http://laveala.proj.ufsm.br/mod/feedback/analysis.php? $\mathrm{id}=1731 \&$ courseid\&do_show=analysis $>$ 
Figura 3: Avaliação do material didático do $M O O C$

Fonte $^{5}$

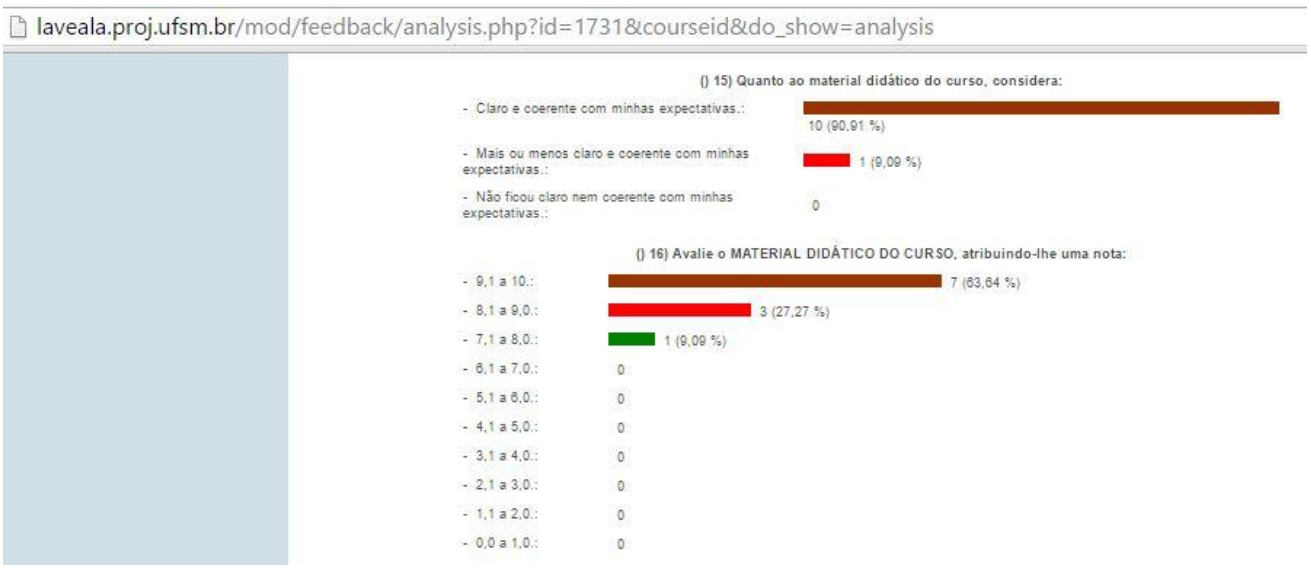

Da sua análise, obteve-se o seguinte resultado: 10 cursistas consideraram o material didático "claro e coerente com suas expectativas"; 7 cursistas atribuíram-lhe a nota de 9,1 a 10,0; 3, de 8,1 a 9,0; e um deles atribui-lhe de 7,1 a 8,00. Assim, com base nesses dados de avaliação, julgou-se que o material didático foi considerado ótimo.

Portanto, após a análise e descrição dos dados obtidos na pesquisa de avaliação do $M O O C$ e do seu material didático hipermídia, percebeu-se que ambos proporcionaram processo de ensino-aprendizagem mediado pelas TER, com vistas a promover não só a formação profissional, mas também o aprimoramento de conhecimentos acerca da redação oficial em LibreOfffice Writer.

\section{Considerações Finais}

Após realizar esta pesquisa, refletiu-se sobre as suas contribuições para o desenvolvimento pessoal e profissional dos envolvidos, que consistiu no conhecimento acerca de $M O O C$ como uma alternativa viável-possível de se aperfeiçoar por meio da EAD, visto que o conhecimento pode ser estabelecido e compartilhado em rede.

Já no que diz respeito ao "MOOC de Redação Oficial em LibreOffice Writer", observou-se que a mediação pedagógica pôde contribuir não só com a inserção dessa ferramenta às práticas profissionais, como também para o aperfeiçoamento da escrita de documentos oficiais. Assim, evidenciou-se que houve relevância social pelo fato desta

5 Moodle Laveala, disponível no link: <http://laveala.proj.ufsm.br/mod/feedback/analysis.php? id=1731\&courseid\&do_show=analysis $>$. 
pesquisa ter trazido contribuições aos envolvidos com relação à possibilidade de promover o desenvolvimento pessoal e profissional em rede.

Este estudo também trouxe contribuição científica no que diz respeito às ações pedagógicas que podem ser promovidas na perspectiva da educação como prática da Liberdade (Freire, 1967). Constatou-se que os estudantes, seja da modalidade de ensino presencial ou à distância, podem ser tratados como sujeitos ativos no processo de ensino-aprendizagem. Nesse viés, acredita-se que, mesmo a educação sendo mediada por TER e sem a presença física do professor, é possível proporcionar um espaço aberto ao diálogo-problematizador, que, mesmo na EAD, é possível contribuir para que os cidadãos/cursistas sejam críticos e reflexivos diante dos conteúdos abordados.

Nessa perspectiva, ao propor atividades em rede, percebe-se a relevância de relacioná-las a contextos existenciais, ou seja, à realidade vivida dos estudantes (Freire, 1996). Isto é uma forma de educação como prática da liberdade (Freire, 1967), a qual proporciona situações existenciais para que possam ser relacionadas ao conteúdo e possam trazer sentido aos estudantes. E foi isso o que o presente " $M O O C$ de Redação Oficial em LibreOffice Writer" promoveu: um desenvolvimento pessoal e profissional em rede na perspectiva da educação libertadora, de preparar os seus cursistas para refletir acerca dos conteúdos abordados em seus contextos existenciais, como também para (re)significá-los em sua prática, sendo um movimento livre para (re)pensá-la e aplicá-la em sua realidade, ou seja, de gerar ação-reflexão-ação em seu contexto pessoal e profissional.

Com a realização deste estudo, verificou-se que os objetivos propostos foram alcançados nas seguintes medidas: 1) o de "promover a formação profissional em rede através de um MOOC de redação de textos oficiais em LibreOffice Writer, com material didático hipermídia" foi bem-sucedido, uma vez que foi promovida uma formação em rede considerada pelos cursistas como excelente; 2) o de "disseminar e incentivar a integração do LibreOffice Writer às práticas profissionais" foi atingido de forma satisfatória, uma vez que os cursistas manifestaram interesse em integrar este programa às suas práticas. Porém, não tem como garantir que de fato isso ocorrerá, pois não se vislumbra um acompanhamento posterior à realização do curso; e 3) o de "explorar o potencial do LibreOffice Writer para a produção de textos por meio de material didático hipermídia" foi bem-sucedido, uma vez que os cursistas o consideraram "ótimo".

Portanto, o MOOC expande a oferta de formação mediada por TER, que, além de possibilitar o acesso a um grande número de participantes, é uma ferramenta 
potencializadora para, através da prática da liberdade, inovar a formação profissional em rede. No entanto, levantam-se as seguintes questões, que servem para pesquisas futuras: qual o potencial dos $M O O C$ para o processo ensino-aprendizagem? Será que em MOOC faz-se necessário a avaliação das atividades? Outros MOOCs podem ser viabilizados na perspectiva da educação como prática da liberdade? Será que um $M O O C$, na perspectiva do diálogo-problematizador, será bem-sucedido com 200 ou mais participantes? Eis alguns questionamentos desafiadores, que nos conduzem a novas investigações acerca das potencialidades de $M O O C$ para a promoção da educação mediada por TER.

\section{Referências}

ABEGG, I.; BASTOS, F. P.; MÜLLER, F. M. Educação como prática da liberdade e movimento software livre: produção colaborativa mediada pelas TIC. Revista FACED, Salvador, n. 15, jan./jul. 2009. Disponível em: <http://www.portalseer.ufba.br/index.php/entreideias/article/view/3445/3519>. Acesso em: 25 mar. 2017.

ALBERTI, T. F. et al. Oportunidades, perspectivas e limitações dos MOOC no âmbito da UAB/UFSM. In: ESUD 2013 - Congresso Brasileiro De Ensino Superior A Distância, 10., 2013, Belém/PA. Anais Congresso Brasileiro de Ensino Superior a Distância, 10., Belém/PA, jun. 2013. p. 1-13. Disponível em: <http://www.aedi.ufpa.br/esud/trabalhos/poster/AT1/114256.pdf>. Acesso em: $27 \mathrm{dez}$. 2015.

BARIN, C. S.; BASTOS, F. P. Problematização dos MOOC na atualidade: Potencialidades e Desafios. Revista Renote, Porto Alegre, v. 11, n. 3, dezembro/2013. p. 1-10. Disponível em: <http://seer.ufrgs.br/index.php/renote/article/view/44707/28546>. Acesso em: 11 nov. 2015.

BECKER, A. M. Rede de Formação e Desenvolvimento Profissional e Constituição de Comunidade: um diálogo sobre o percurso formativo inicial em educação a distância. Revista Renote, Porto Alegre, v. 11, n. 1, jul. 2013. Disponível em: <http://seer.ufrgs.br/renote/article/viewFile/41710/26459>. Acesso em: 13 nov. 2014.

CARR, W.; KEMMIS, S. Becoming Critical Education, Knowledge and Action Research. New York, USA: Deakin University Press, 1986.

FREIRE, P. Educação como prática da liberdade. Rio de Janeiro: Paz e Terra, 1967.

FREIRE, P. Pedagogia da autonomia: saberes necessários à prática educativa. 25. ed. São Paulo: Paz e Terra, 1996.

GABRIEL, M. Educ@r: a (r) evolução digital na educação. São Paulo: Saraiva, 2013. 
INUZUKA, M. A.; DUARTE, R. T. Produção de REA apoiada por MOOC. In: SANTANA, B.; ROSSINI, C. e PRETTO, N. L. (Org.). Recursos Educacionais Abertos: práticas colaborativas políticas públicas.1. ed., 1 imp. - Salvador: Edufba; São Paulo: Casa da Cultura Digital. 2012, p. 193-217.

KENSKI, V. M. Educação e tecnologias: O novo ritmo da informação. 8. ed. Campinas, SP: Papirus, 2012.

MALLMANN, E. M. et al. Mooc mediado por REA: prática da liberdade nos programas de capacitação continuada no ensino superior. In: Colóquio Luso-Brasileiro De Educação A Distância e E-learning, 3., 2013, Lisboa, PT. Anais Colóquio LusoBrasileiro de Educação a Distância e E-learning, 3., Lisboa, PT: Universidade Aberta de Portugal, v. 1, 2013. p. 1-19. Disponível em: <https://repositorioaberto.uab.pt/bitstream/10400.2/3076/1/Mooc.pdf >. Acesso em: 24 nov. 2015.

POCHMANN, M. Trabalho e formação. Revista Educação \& Realidade, Porto Alegre, v. $37, \quad$ n. 2, p. 491-508, maio/ago. 2012. Disponível em: <http://seer.ufrgs.br/index.php/educacaoerealidade/article/view/30490/19420>. Acesso em: 13 set. 2014.

UNIVERSIDADE FEDERAL DE SANTA MARIA. Laboratório Ambiente Virtual de Ensino-Aprendizagem Livre e Aberto (Laveala). Disponível em: <http:laveala.proj.ufsm.br>. Acesso em: 13 jun. 2016.

VELOSO, R. Tecnologias da informação e da comunicação: desafios e perspectivas. São Paulo: Saraiva, 2011.

\section{Como referenciar este artigo}

BONORINO, Liliane Silveira; ABEGG, Ilse. Formação profissional em rede: MOOC de redação oficial em LibreOffice Writer. Revista Ibero-Americana de Estudos em Educação, Araraquara, v. 12, n. 2, p. 1069-1084, 2017. Disponível em: <http://dx.doi.org/10.21723/riaee.v12.n2.9111>. E-ISSN: 1982-5587.

Recebido em: 02/12/2016

Aprovação final em: 04/04/2017 